\title{
PEMANFAATAN BEBERAPA PERANGKAP WARNA BERPEREKAT DALAM MENGENDALIKAN HAMA PADA TANAMAN KEDELAI VARIETAS WILIS
}

\author{
The Utilization of Several Colour Adhesive Traps In Controlling Pests on \\ Soybean Wilis Variety \\ Iqbal Erdiansyah, Wahyu Winarno, Nanang Setyo Pambudi \\ Program Studi Teknologi ProduksiTanaman Pangan \\ Politeknik Negeri Jember \\ e-mail: iqbal@polije.ac.id; wahyuwinarno@polije.ac.id; nanangtpp22@gmail.com
}

\begin{abstract}
ABSTRAK
Penelitian bertujuan untuk mengetahui keefektifan pengendalian hama menggunakan perangkap warna berperekat terhadap tanaman kedelai varietas wilis Penelitian ini dilaksanakan pada bulan Agustus 2017 sampai dengan bulan Oktober 2017. Bertempat di Desa Ampel Krajan Kecamatan Wuluhan Kabupaten Jember. Penelitian ini dilakukan dengan menggunakan Rancangan Acak Kelompok (RAK) Non Faktorial yaitu pemberian perekat berwarna yang terdiri dari 5 level yang diulang sebanyak 6 kali yaitu warna kuning, warna hijau, warna putih, warna merah, dan warna biru. Pengamatan dilakukan terhadap parameter macam-macam serangga, jumlah hama dan intensitas serangan hama. Hasil penelitian menunjukan bahwa Pemanfaatan beberapa perangkap pada tanaman kedelai varietas Willis memberikan pengaruh nyata (significant) terhadap parameter jumlah hama yang terperangkap. Perangkap warna kuning merupakan perangkap warna yang efektif karena hama lebih tertarik pada warna kuning.
\end{abstract}

Kata Kunci: Perangkap Warna Berperekat, Kedelai Varietas Wilis

\begin{abstract}
The research determine the effectiveness of pest control using adhesive colour traps on soybean plantwilis variety This study was carried out in August 2017 until October 2017. Located in Ampel Village, Wuluhan District, Jember Regency. This final project research was carried out using Non Factorial Randomized Block Design (RBD) arrangement by giving the coloured adhesive consisting of 5 levels which were repeated 6 times namely yellow, green, white, red and blue. The observation was made on parameters of types of insects, number of pests and intensity of pest attacks. The results showed that the the number of colour traps utilization in controlling pests on soybean plant wilis variety had a significant effect on the parameters of the number of trapped pests. Yellow traps are effective colour traps because pests are more interested in yellow.
\end{abstract}

Keywords:Adhesive Colour Trap, Soybean Wilis Variety

\section{PENDAHULUAN}

Kedelai varietas wilis merupakan salah satu varietas kedelai lokal unggul yang sering ditanam oleh para petani kedelai, kedelai varietas wilis mempunyai produksi 1,75 ton per hektar, kedelai varietas wilis ini dimanfaatkan sebagi olahan pangan yaitu sebagai tempe maupun susu kedelai dan olahan yang lain. 
Aphis glycines (soybean aphid) merupakan hama yang dapat berkembang sangat cepat dan mempunyai koloni yang cukup besar dan dapat menyebabkan kehilangan hasil panen mencapai 58\% pada tanaman kedelai (Prawidya et al., 2013). A. glycines dapat mengisap cairan pada daun, batang, dan polong. A.glycines banyak ditemui di permukaan bawah daun untuk tempat persembunyian (Hendrival, 2014). A. glycines yang menyerang tanaman kedelai dapat menyebabkan penurunan kapasitas fotosintesis kualitas polong yang dihasilkan tanaman kedelai. Melati et al.(2005) polong yang terbentuk berkurang, berukuran kecil, dan berbelang(Arifin, 2006).

Untuk mencegah hama tersebut sampai saat ini petani masih mengendalikan dengan pestisida kimia berbahaya bagi lingkungan dan manusia, sehingga salah satu cara untuk pengendalian hama yaitu menggunakan perangkap warna berperakat. Metode yang digunakan ini lebih efektif dibandingkan metode satuan unit contoh, karena hama yang berada pada sekitar tanaman langsung terperangkap.

\section{METODE PENELITIAN}

Penelitian ini telah dilaksanakan pada bulan Agustus 2017 sampai dengan bulan Oktober 2017. Tempat Penelitian di Desa Ampel Krajan Kecamatan Wuluhan Kabupaten Jember.

\section{RancanganPenelitian}

Penelitian ini dilakukan dengan menggunakan Rancangan Acak Kelompok (RAK) Non Faktorial yaitu pemberian perekat berwarna yang terdiri dari 5 level yang diulang sebanyak 6 kali. Adapun faktor tersebut yaitu: A1 : Warna Kuning; A2 : Warna Hijau; A3 : Warna Putih; A4 : Warna Merah; A5 : Warna Biru.

Analisis data yang dilakukan adalah dengan menggunakan sidik ragam (Uji F). Apabila hasil analisisnya menunjukkan berbeda nyata maka dilanjutkan pengujian lanjut dengan menggunakan uji lanjut DMRT (Duncan Multiple Range Test) dengan taraf 5\%

\section{Parameter Pengamatan}

Kelimpahan serangga, dilakukan pada saat serangga yang menempel pada perangkap tersebut bertujuan untuk mengetahui jumlah dan jenis serangga yang terdapat pada tanaman kedelai.

Jumlah hama, Untuk mengetahui jumlah hama dan hama yang dominan yang berada di sekitar tanaman kedelai.

Intensitas serangan hama, Pengamatan intensitas serangan hama dilakukan seminggu sekali yaitu dengan cara mengukur persentase daun yang terserang ulat disetiap plot. 


\section{HASIL DAN PEMBAHASAN}

\section{Kelimpahan Serangga}

Hasil sidik ragam menunjukkan bahwa $\mathrm{F}$ Hitung perlakuan lebih besar dari $\mathrm{F}$ tabel $1 \%$, hal tersebut menunjukkan perlakuan yang digunakan memberikan pengaruh sangat nyata (high significant), sehingga perlu dilakukan uji lanjut DMRT (Duncan's Multiple Range Test) dengan taraf 5\%. Hasil uji lanjut fakor Perlakuan dalam tabel di bawah ini:

Tabel 1. Pengaruh warna trap terhadap kelimpahan serangga,

\begin{tabular}{lc}
\hline \multicolumn{1}{c}{ Perlakuan } & Rata-rata \\
\hline A5 Biru & $9,83 \mathrm{a}$ \\
A4 merah & $12 \mathrm{ab}$ \\
A3 putih & $14,5 \mathrm{ab}$ \\
A2 hijau & $19,83 \mathrm{~b}$ \\
A1 kuning & $27,16 \mathrm{c}$ \\
\hline
\end{tabular}

Keterangan : Angka-angka yang diikuti huruf kecil yang berbeda menunjukkan berbeda nyata menurut uji DMRT dengan taraf 5\%

\section{Jumlah Hama Terperangkap}

Pemanfaatan beberapa perangkap warna pada tanaman kedelai memberikan pengaruh terhadap penangkapan hama pada tanaman kedelai. Berdasarkan grafik di atas menunjukkan bahwa perangkap yang paling efektif untuk menangkap hama adalah perangkap berwarna kuning, hal tersebut sesuai dengan yang ditunjukkan diagram bahwa perekat kuning mampu menangkap hama.

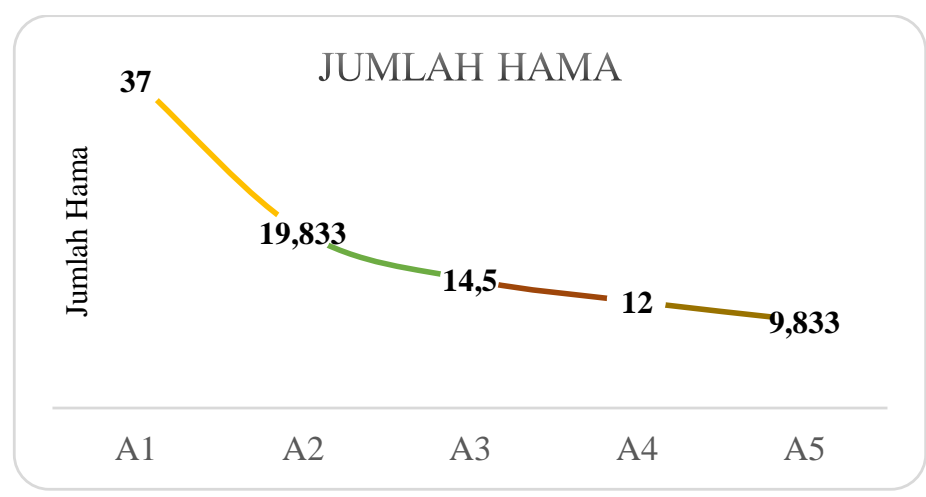

Gambar 1. Jumlah hama yang terperangkap dalam berbagai macam warna berperekat

Populasi hama yang terperangkap pada perangkap berwarna kuning lebih tinggi dibandingkan dengan populasi yang tertangkap pada perangkap berwarna lainnya. Menurut Munandar et al.(2018) bahwa hama lebih tertarik pada warna kuning, hal tersebut dikarenakan perangkap berwarna kuning memiliki ketertarikan dengan panjang gelombang yang dimiliki oleh warna tersebut sehingga hama lebih menyukai warna 
kuning. Rante et al.(2017) menyatakan bahwa ketertarikan hama pada suatu warna sangat tergantung pada panjang gelombang dari warna tersebut.

\section{Keragaman Serangga}

Hama merupakan organisme penganggu tanaman yang dapat menimbulkan kerugian pada tanaman budidaya, hal tersebut dikarenakan hama dapat mneurunkan produktivitas pada tanaman kedelai. Hama yang menyerang tanaman kedelai diantaranya yaitu kaper, lalat bibit, kutu daun, lalat buah, kutu kebul, kepik hitam, kepik hijau, capung dan laba-laba. Munandar et al.(2018)setiap Jenis inang pada cendawan entomopatogen petani belum bisa mengetahui.Menurut Prayogo (2006) hama Hemiptera dan ordo Lepidoptera waktu penyerangan pada stadia instar (nimfa) serangga yang terpengaruhi akhirnya menentukan keefektifan cendawan. sinar matahari maupun sinar ultra violet yang bisa merusak konidia cendawan dan kondisi lingkungan, curah hujan juga dapat mempengaruhi.

Ketertarikan serangga terhadap warna dapat dijadikan acuan untuk usaha pengendalian, penggunaan perangkap kertas berwarna merupakan salah satu cara untuk melihat serangga yang ada di areal lahan, sehingga dapat memudahkan untuk melakukan identifikasi hama. Dari literatur menyebutkan ketertarikan serangga terhadap beberapa warna merupakan salah satu perilaku serangga di alam. cara untuk memberi daya tarik serangga terhadap warna yaitu dengan cara pemberian perangkap warna yang berbeda. Warna media yang digunakan harus dapat memberi pantulan cahaya atau adanya zat penarik Lukmanul et al.(2016) Perangkap warna kuning dapat menarik serangga jenis lalat buah, lalat bibit, kapar, kutu daun dan kupu-kupu. Sedangkan pada perangkap warna putih serangga yang mempel adalah lalat buah, lalat bibit, capung, kutu daun, kapar dan burung.

Perangkap warna merah dapat menarik serangga jenis lalat buah, kapar, kutu daun dan kepik hijau. Perangkap warna hijau dapat menarik serangga jenis kapar, lalat buah, kutu daun dan lalat bibit. Tidak hanya itu, ada beberapa jenis serangga yang merusak daun pada masa vegetatif tanaman yaitu hama Black policoan dan belalang. Sedangkan jenis predator yang terdapat selama budidaya tanaman kedelai adalah labalaba. 
Tabel 2 Keragaman Serangga

\begin{tabular}{|c|c|c|}
\hline \multirow{2}{*}{$\begin{array}{l}\text { Jenis Serangga } \\
\text { Lalat Buah }\end{array}$} & \multicolumn{2}{|c|}{ Klasifikasi } \\
\hline & Kingdom & Animalia \\
\hline \multirow{6}{*}{ (Drosophila melanogaster) } & Phylum & Arthropoda \\
\hline & Class & Insecta \\
\hline & Ordo & Diptera \\
\hline & Family & Drosophilidae \\
\hline & Genus & Drosophila \\
\hline & Species & Drosophila melanogaster \\
\hline \multirow[t]{6}{*}{ Lalat Bibit (Ophiomyia phaseoli) } & Phylum & Arthropoda \\
\hline & Class & Insecta \\
\hline & Ordo & Diptera \\
\hline & Family & Agromyzidae \\
\hline & Genus & Ophiomyia \\
\hline & Species & Ophiomyia phaseoli \\
\hline \multirow[t]{6}{*}{ Kutu Daun (Aphis cracivora Koch) } & Phylum & Arthropoda \\
\hline & Class & Insecta \\
\hline & Ordo & Homoptera \\
\hline & Family & Aphididae \\
\hline & Genus & Aphis \\
\hline & Species & Aphis craccivora \\
\hline \multirow[t]{7}{*}{ Kapar (Plutella xylostella L.) } & Kingdom & Animalia \\
\hline & Phylum & Arthropoda \\
\hline & Class & Insecta \\
\hline & Ordo & Lepidoptera \\
\hline & Family & Plutellidae \\
\hline & Genus & Plutella \\
\hline & Species & Plutella xylostella $L$. \\
\hline \multirow[t]{7}{*}{ Burung (Lonchura punctulata) } & Kingdom & Animalia \\
\hline & Phylum & Chordata \\
\hline & Class & Aves \\
\hline & Order & Passeriformes \\
\hline & Family & Estrildidae \\
\hline & Genus & Lonchura \\
\hline & Species & Lonchura punctulata \\
\hline \multirow[t]{9}{*}{ Kepik Hijau (Nezara viridula) } & Kingdom & Animalia \\
\hline & Filum & Arthropoda \\
\hline & Class & Insecta \\
\hline & Ordo & Hemiptera \\
\hline & Sub ordo & Heteroptera \\
\hline & Family & Pentatomidae \\
\hline & Sub family & Pentatominae \\
\hline & Genus & Nezara \\
\hline & Species & Nezara viridula \\
\hline
\end{tabular}




\section{Intensitas Serangan Hama}

Pengamatan intensitas serangan hama dilakukan seminggu sekali yaitu dengan cara mengukur persentase daun yang terserang ulat disetiap plot. Data diperoleh dari pengamatan yang kemudian dianalisa menggunakan sidik ragam.

Berdasarkan rekapitulasi Hasil Analisis Sidik Ragam menunjukkan bahwa semua parameter intensitas serangan hama pada 2 MST, 3 MST, 4 MST, 5 MST, 6 MST, 7 MST, 8 MST, 9 MST, 10 MST menunjukkan berbeda nyata (non significant), hal tersebut disajikan pada tabel 4.6 berikut ini:

Berdasarkan hasil parameter Intensitas Serangan Hamadapat dilihat grafik ratarata hasil pengamatan Intensitas Serangan Hamatanaman kedelai pada Grafik 4 di bawah ini:

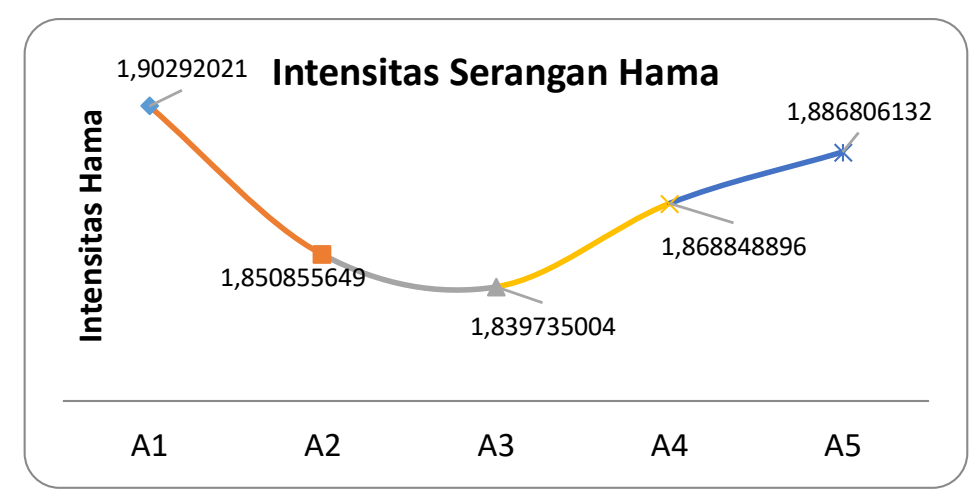

Gambar 2. Intensitas Serangan Hama pada masing-masing perlakuan

Berdasarkan hasil sidik ragam diatas menunjukkan bahwa F Hitung perlakuan lebih kecil dari $\mathrm{F}$ tabel 5\%, hal tersebut menunjukkan bahwa perlakuan yang digunakan tidak memberikan pengaruh yang nyata terhadap tanaman kedelai. Pada pertumbuhan vegetatif, hama dominan menyerang yang tanaman kedelai adalah belalang kayu (Valanga nigricornis).

Hama tersebut tidak melekat pada perekat melainkan hanya singgah pada daun. Untuk itu pada perlakuan perekat berwarna yang diaplikasikan pada tanaman kedelai tidak memberikan pengaruh nyata terhadap tanaman kedelai. Sedangkan pada fase generatif hama dominan yang menyerang tanaman kedelai adalah hama black polycaon (Polycaon stouti).

\section{KESIMPULAN}

1. Pemanfaatan perangkap warna pada tanaman kedelai varietas Willis memberikan pengaruh nyata (significant) terhadap parameter jumlah hama yang terperangkap. 
Perangkap warna kuning merupakan perangkap warna yang efektif karena hama lebih tertarik pada warna kuning.

2. Hama dominan yang menyerang tanaman kedelai pada fase vegetatif adalah hama belalang kayu (Valanga nigricornis) sedangkan pada fase generatif hama dominan yang menyerang adalah hama black polycaon (Polycaon stouti).

\section{DAFTAR PUSTAKA}

Arifin, M. 2006. Kompatibilitas SINPV dengan HaNPV dalam Pengendalian Ulat Grayak dan Ulat Pemakan Polong Kedelai. Penelitian Pertanian Tanaman Pangan, 25(1). pp.65-71.

Destarianto, P., E. Yudaningtyas, and S.H. Pramono. 2013. Penerapan Metode Inference Tree dan Forward Chaining dalam Sistem Pakar Diagnosis Hama dan Penyakit Kedelai Edamame Berdasarkan Gejala Kerusakannya. Jurnal EECCIS, 7(1). pp.21-27.

Hendrival, Latifah, and Idawati. 2014. Pengaruh Pemupukan Kalium Terhadap Perkembangan Populasi Kutu Daun (Aphis glycines Matsumura) dan Hasil Kedelai. Jurnal Floratek, 9. pp.83-92.

Lukmanul Hakim, Erdi Surya, A.M. 2016. Pengendalian Alternatif Hama Serangga Sayuran dengan Menggunakan Perangkap Kertas. Jurnal Agro, 3(2). pp.21-33.

Melati, M. and W. Andriyani. 2005. Pengaruh Pupuk Kandang Ayam dan Pupuk Hijau Calopogonium mucunoides Terhadap Pertumbuhan dan Produksi Kedelai Panen Muda yang Dibudidayakan Secara Organik. Buletin Agronomi, 33(2). pp.8-15.

Munandar, M.A., R. Hestiningsih, and N. Kusariana. 2018. Perbedaan Warna Perangkap Pohon Lalat Terhadap Jumlah Lalat Yang Terperangkap Di Tempat Pembuangan Akhir (TPA) Sampah Jatibarang Kota Semarang. Jurnal Kesehatan Masyarakat, 6(4). pp.157-167.

Patty, J.A. 2012. Efektivitas Metil Eugenol terhadap Penangkapan Lalat Buah (Bactrocera dorsalis) pada Pertanaman Cabai. Agrologia, 1(1). pp.69-75.

Permanasari, I. and D. Kastono. 2012. Pertumbuhan Tumpangsari Jagung dan Kedelai Pada Perbedaan Waktu Tanam dan Pemangkasan Jagung. Jurnal Agroteknologi, 3(1). pp.13-20.

Prayogo, Y. 2006. Upaya mempertahankan keefektifan cendawan entomopatogen untuk mengendalikan hama tanaman pangan. Jurnal Litbang Pertanian, 25(2). pp.4754.

Rante, C.S. and G.S.J. Manengkey. 2017. Preferensi Hama Thrips sp. (Thysanoptera: Thripidae) terhadap Perangkap Berwarna pada Tanaman Cabai. Eugenia, 23(3). pp.113-119.

Sudirman, A. Rasyad, and T. Nurhidayah. 2015. Pengaruh Pemberian Giberelin terhadap Pertumbuhan dan Produksi Empat Varietas Kedelai (Glycine max L . Merrill). Jurnal Agrotek, 4(2). pp.47-54. 